\title{
A Role for Diminished GABA Transporter Activity in the Cortical Discharge Phenotype of MeCP2-Deficient Mice
}

\author{
Liang Zhang ${ }^{1,2,3}$, Robert G Wither ${ }^{4,5}$, Min Lang ${ }^{2,4,5}$, Chiping Wu ${ }^{1,4}$, Elena Sidorova-Darmos, \\ Hristo Netchev ${ }^{4}$, Catherine B Matolcsy ${ }^{4}$, Orlando Carter Snead ${ }^{2,3}$ and James H Eubanks ${ }^{*, 2,4,5,6}$ \\ 'Division of Fundamental Neurobiology, Toronto Western Research Institute, University Health Network, Toronto, ON, Canada; ${ }^{2}$ University of \\ Toronto Epilepsy Research Program, University of Toronto, Toronto, ON, Canada; ${ }^{3}$ Department of Medicine (Neurology), University of Toronto, \\ Toronto, ON, Canada; ${ }^{4}$ Division of Genetics and Development, Toronto Western Research Institute, University Health Network, Toronto, ON, \\ Canada; ${ }^{5}$ Department of Physiology, University of Toronto, Toronto, ON, Canada; ${ }^{6}$ Department of Surgery (Neurosurgery), University of Toronto, \\ Toronto, ON, Canada
}

\begin{abstract}
Cortical network hyper-excitability is a common phenotype in mouse models lacking the transcriptional regulator methyl-CPG-binding protein 2 (MeCP2). Here, we implicate enhanced GABA $A_{B}$ receptor activity stemming from diminished cortical expression of the GABA transporter GAT-I in the genesis of this network hyper-excitability. We found that administering the activity-dependent GABA ${ }_{B}$ receptor allosteric modulator GS-39783 to female Mecp $2^{+/-}$mice at doses producing no effect in wild-type mice strongly potentiated their basal

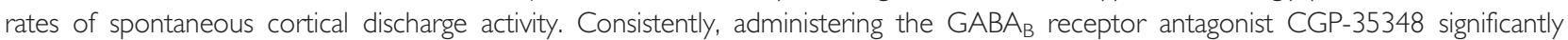
decreased basal discharge activity in these mice. Expression analysis revealed that while $G A B A_{B}$ or extra-synaptic $G A B A_{A}$ receptor prevalence is preserved in the MeCP2-deficient cortex, the expression of GAT-I is significantly reduced from wild-type levels. This decrease in GAT-I expression is consequential, as low doses of the GAT-I inhibitor NO-7I I that had no effects in wild-type mice strongly exacerbated cortical discharge activity in female Mecp $2^{+/-}$mice. Taken together, these data indicate that the absence of MeCP2 leads to decreased cortical levels of the GAT-I GABA transporter, which facilitates cortical network hyper-excitability in MeCP2-deficient mice by increasing the activity of cortical $G A B A_{B}$ receptors.

Neuropsychopharmacology (2016) 4I, |467-1476; doi:I0.1038/npp.20I5.323; published online I8 November 2015
\end{abstract}

\section{INTRODUCTION}

Methyl-CPG-binding protein 2 (MECP2) is a ubiquitously expressed epigenetic factor that regulates normal transcriptional activity. Loss-of-function mutations of MECP2 can cause Rett syndrome, which is one of the leading genetic causes of severe intellectual disability in females (Amir et al, 1999). In addition to Rett syndrome, alterations in normal $\mathrm{MeCP} 2$ prevalence or function have also been implicated in a host of neurodevelopmental conditions (Neul, 2012; Van Esch et al, 2005). Given the commonality of involvement of altered $\mathrm{MeCP} 2$ function in this spectrum of neural disorders, delineating the mechanisms through which $\mathrm{MeCP} 2$ dysfunction leads to the development of specific neurological phenotypes may shed light upon pathogenesis cascades common to a number of genetic and non-genetic conditions that share overlapping phenotypes.

*Correspondence: Dr J Eubanks, Toronto Western Hospital, 8KD-417, 60 Leonard Avenue, Toronto, ON M5T 2S8, Canada, Tel: + I 416603 5800, ext. 2933, Fax: + I 416 6035745 ,

E-mail: jeubanks@uhnres.utoronto.ca

Received 21 May 2015; revised 13 September 2015; accepted I October 2015; accepted article preview online 26 October 2015
To facilitate such investigations, several mouse models have been developed that either lack $\mathrm{MeCP} 2$ or express a clinically-relevant mutant form of MeCP2 (Katz et al, 2012). These mice display a constellation of behavioral and neurological deficits; many of which mirror symptoms also seen in patients with different types of MECP2 mutations (Katz et al, 2012). One feature commonly associated with the absence of $\mathrm{MeCP} 2$ is neural network hyper-excitability (Zhang et al, 2008; Calfa et al, 2011; Ward et al, 2011; McLeod et al, 2013). We have previously reported rhythmic cortical spike and wave EEG discharges in both male and female mice expressing a null Mecp2 allele (D'Cruz et al, 2010; Wither et al, 2012; Lang et al, 2014). Shahbazian et al (2002) also reported myoclonic jerks coupled with high-amplitude bilateral cortical spike and wave discharges in the Mecp $2^{308 / y}$ mouse, and Goffin et al (2011) reported evidence for cortical network hyper-excitability in the Mecp $2^{T 158 A / y}$ mouse model. There are also circuitry-specific components to the genesis of these discharges. Ward et al (2011) showed cortical network hyper-excitability in mice globally lacking $\mathrm{MeCP} 2$, but not in mice selectively lacking $\mathrm{MeCP} 2$ from HOX-B1 hindbrain neurons, whereas Goffin et al (2014) showed network hyper-excitability in mice lacking MeCP2 only in forebrain inhibitory neurons, but not 
in mice selectively lacking $\mathrm{MeCP} 2$ in excitatory forebrain neurons. These latter data suggest that GABAergic circuits may be instrumental for defining network hyper-excitability in the MeCP2-deficient brain, but to date, the underlying mechanisms for how hyper-excitable neural networks arise in these models remain poorly understood. Using cortical discharge activity as an index of network hyper-excitability, our present study investigates how specific GABAergic signaling mechanisms influence the genesis and regulation of cortical network hyper-excitability in MeCP2-deficient mice. Our results indicate that enhanced $\mathrm{GABA}_{\mathrm{B}}$ receptor activity stemming at least in part from decreased cortical expression of the GABA transporter GAT-1 have a key role in the genesis of MeCP2-deficient cortical network hyper-excitability.

\section{MATERIALS AND METHODS}

\section{Ethics Statement}

All animal experimentation was conducted in accordance with the guidelines of the Canadian Council of Animal Care, and the work was thoroughly reviewed and approved by local animal care committees before initiation (UHN Animal Use Protocol 1321.7).

\section{Animal Subjects}

Female and male Mecp $2^{\text {tm1.1Bird }}$ mice (Guy et al, 2001) were used in this study. These animals were obtained from Jackson Laboratories (Bar Harbor, ME, USA) or bred in-house, and maintained on a pure $\mathrm{C} 57 \mathrm{Bl} / 6 \mathrm{~J}$ background. Male and female mice were subjected to the experimental procedures described below when mice displayed clear Rettlike behavioral phenotypes (Katz et al, 2012); male Mecp $2^{\text {tm1.1Bird }}$ mice were studied between 60 and 80 days, and female Mecp $2^{\text {tm1.1Bird }}$ mice were studied between 14 and 18 months of age. Gender and age-matched wild-type mice on a pure $\mathrm{C} 57 \mathrm{Bl} / 6 \mathrm{~J}$ background served as controls. Genotyping of these mice was done via PCR as described previously (Guy et al, 2001; Jugloff et al, 2008). All animals were housed in a vivarium that was maintained between 22 and $23{ }^{\circ} \mathrm{C}$, and employed a standard 12-h light on/off cycle commencing at $0600 \mathrm{~h}$.

\section{Implantation Surgery}

Experimental and control animals were implanted with polyimide-insulated stainless steel microelectrodes $(125 \mu \mathrm{m})$ in somatosensory cortex (Bregma, $-0.8 \mathrm{~mm}$; lateral, $1.8 \mathrm{~mm}$; depth, $1.5 \mathrm{~mm}$ ) following the procedures outlined previously (Wu et al, 2008; D'Cruz et al, 2010; Lang et al, 2013). The reference electrode was implanted superficially into the frontal brain area (Bregma, $+2.8 \mathrm{~mm}$; lateral, $1.8 \mathrm{~mm}$; depth, $0.5 \mathrm{~mm}$ ). Following implantation, animals were allowed at least 7 days of post-surgical recovery before further experimentation.

\section{EEG Recording and Analysis}

EEG recordings were collected as described previously (D'Cruz et al, 2010; Lang et al, 2013), and data analyzed using the pCLAMP software (Molecular Devices, Sunnyvale,
CA, USA). All EEG recordings were made from freely moving mice for different periods of time. For female $M e c p 2^{+/-}$mice, the recording sessions were $2 \mathrm{~h}$ long on consecutive days. For male Mecp2 $2^{-/ y}$ mice, discharge profiles were assessed for a minimum of $1 \mathrm{~h}$ per day, with at least 1 week between sessions. For pharmacological characterization, baseline EEG activities were collected for $\sim 30 \mathrm{~min}$ before drug administration, and the drug effects evaluated for $1 \mathrm{~h}$ following administration. A washout period of at least 2 days was employed before a subject was administered any other pharmacological compound.

\section{Characterization of Epileptiform Discharge Events}

Two independent investigators blinded to experimental conditions visually examined EEG traces, and their individual counts were averaged. Concordance rates between the two counters were greater than $90 \%$. Excitatory discharge events were defined as rhythmic spike waveforms, having amplitudes of at least 1.5-fold background, durations of at least $0.4 \mathrm{~s}$, and frequencies between 6 and $10 \mathrm{~Hz}$ (D'Cruz et al, 2010; Wither et al, 2012, 2013; Lang et al, 2013, 2014). Long discharge events were defined similarly to typical discharge events, but required a minimum duration of $5 \mathrm{~s}$ and an average frequency of between 4 and $6 \mathrm{~Hz}$. The frequency of discharges was determined by generating spectral plots using the Fast Fourier Transformation (FFT) function in pCLAMP (Molecular Devices) with rectangular binning, 50\% window overlap, and a spectral resolution of $0.5 \mathrm{~Hz}$.

\section{Drugs and Chemicals}

Unless specified otherwise, all general reagents and buffers were obtained from Sigma-Aldrich (Mississauga, ON, Canada). The drugs and dosages used in this study were CGP-35348 (Tocris, Bristol, UK) at $100 \mathrm{mg} / \mathrm{kg}$; GS-39783 (Tocris) at 2.5 and $5 \mathrm{mg} / \mathrm{kg} ; 4,5,6,7$-tetrahydroisoxazolo[5,4c]pyridine-3-ol (THIP) (Sigma-Aldrich) at $5 \mathrm{mg} / \mathrm{kg}$; and NO-711 (Sigma-Aldrich) at 1 and $2.5 \mathrm{mg} / \mathrm{kg}$. All drugs were diluted in saline and administered intraperitoneally to the animals.

\section{Immunoblotting}

Mice were killed by isoflurane overdose, and their brains isolated rapidly on ice. Cerebral cortices were isolated and frozen on dry ice before being partially thawed, and homogenized by sequential passage through 20,23 , and $25 \frac{1}{2}$ gauge syringe needles in RIPA buffer $(50 \mathrm{mM}$ Tris-HCl (pH 7.5), $150 \mathrm{mM} \mathrm{NaCl}, 1 \% \mathrm{NP}-40,2 \mathrm{mM}$ EDTA, $0.5 \%$ sodium deoxycholate, and $0.1 \%$ SDS) supplemented with a mixture of protease inhibitors (PMSF $40 \mathrm{ng} / \mathrm{ml}$, Antipain $2 \mathrm{ng} / \mathrm{ml}$, Pepstatin A $2 \mathrm{ng} / \mathrm{ml}$, Leupeptin $20 \mathrm{ng} / \mathrm{ml}$, Aprotinin $20 \mathrm{ng} / \mathrm{ml}$, and MDL28170 $20 \mathrm{ng} / \mathrm{ml}$ ). The crude homogenate was centrifuged at $12000 \mathrm{~g}$ for $5 \mathrm{~min}$ to remove insoluble material, and aliquots of the remaining supernatant collected and stored at $-80^{\circ} \mathrm{C}$ until use. Protein concentrations were determined using the Folin method (Bio-Rad, Hercules, CA, USA; Cat \#500-0116). SDS-PAGE and western blot procedures were conducted as described previously (Asaka et al, 2006; Wither et al, 2013; Sidorova-Darmos et al, 
2014) using the following antibodies and dilutions: anti-GAT-1 (1:1000; Abcam, Cambridge, MA, USA; Cat \#ab426), anti-GABA $\mathrm{A}$ receptor delta subunit (1:1000, Phosphosolutions, Aurora, CO, USA; Cat \#868-GDN), anti-GABA ${ }_{B}$ receptor R2 subunit antibodies (1:1000; Millipore, Temecula, CA, USA; Cat \#AB2255; and 1:200; Alomone Labs, Jerusalem, Israel; Cat \#AGB-002), and anti-GAPDH (1:15000; Chemicon, Billerica, MA, USA; Cat \#MAB374). The HRP-linked secondary antibodies employed were goat-anti-rabbit (1:5000; GE Healthcare, Buckinghamshire, UK; Cat \#NA934), goat-anti-mouse (1:5000; GE Healthcare; Cat \#NA931) or donkey-antiguinea-pig ( 1 : 5000; Jackson ImmunoResearch, West Grove, PA, USA; Cat \#AP193P). Immunoreactivity was visualized by enhanced chemiluminescence (GE Healthcare, Cat \#RPN2106).

\section{Immunoblot Quantification and Analysis}

Immunoreactive protein levels were determined using densitometric analysis as described previously (Asaka et al, 2006; Sidorova-Darmos et al, 2014). In brief, blots were scanned and visualized using Fluor-S MultiImager (Bio-Rad), and the density of the bands was determined using the rectangular density function in the Quantity One (Bio-Rad) analysis program. Film background was subtracted from the calculated specific immunoreactive product to obtain the overall protein density values. Specific target protein levels were then normalized to their corresponding GAPDH protein levels to account for any minor protein loading discrepancies.

\section{Statistical Analysis}

Student's $t$-tests were used for direct comparisons between two normally distributed groups. For comparisons between multiple groups, one-way ANOVA with Bonferroni post hoc correction for multiple comparisons was used. Significance was set at $p<0.05$. Mean and standard error of the mean are presented throughout the text and figures.

\section{RESULTS}

\section{Spontaneous Excitatory Discharge Activity Differs Between Male and Female MeCP2-Deficient Mice}

Cortical EEG recordings were used to identify spontaneous discharge activity in male and female MeCP2-deficient mice. Recordings from 14 - to 18 -month female $\mathrm{Mecp}^{+/-}$mice revealed the presence of one predominant form of excitable discharge activity in all of the mice examined $(n=24)$. These discharges had an average incidence rate of $95.3 \pm 7.7$ events per hour, an average duration of $1.1 \pm 0.1 \mathrm{~s}$, and an average frequency of $7.7 \pm 0.3 \mathrm{~Hz}$ (Figure 1 and Table 1 ). In contrast to the single discharge population seen in female $M e c p 2^{+/-}$mice, however, Mecp2 $2^{-/ y}$ male mice of 50-60 days age $(n=8)$ displayed two distinct discharge populations: a population of short duration discharges similar to those of female $M e c p 2^{+/-}$mice, and a distinct population of longer duration discharges not observed in any of the female $M e c p 2^{+1-}$ mice (Figure 1 and Table 1). The short-duration discharge population had an average incidence rate of
41.2 \pm 8.8 per hour, an average duration of $0.8 \pm 0.1 \mathrm{~s}$, and an average frequency of $6.1 \pm 0.3 \mathrm{~Hz}$. The novel 'long-duration' discharges were present in seven of eight Mecp $2^{-/ y}$ male mice, and had an average duration of $72.8 \pm 14.0 \mathrm{~s} \quad(p<0.0001$ relative to 'short duration' discharges in female Mecp $2^{+/-}$mice, Table 1). The incidence rate of the 'long-duration' discharge events was $2.5 \pm 0.7$ events per hour, which is significantly less frequent than that of the 'short' events seen in the same mice $(p=0.0012$, Table 1). The average frequency of the 'long' discharge waveforms was also significantly slower than that of the 'short' discharges $(5.5 \pm 0.3 \mathrm{~Hz} ; p=0.047$, Table 1$)$. These discharge activities were specific to MeCP2-deficient mice, as no cortical spike and wave discharge activity having at least $0.5 \mathrm{~s}$ duration was observed in any of the 10 male or 22 female wild-type mice examined (Table 1).

\section{Enhancing $\mathrm{GABA}_{\mathrm{B}}$ Receptor Activity Increases Cortical Epileptiform Discharges in Mecp2 ${ }^{+/}$Mice}

Given the network hyper-excitability phenotype observed in mice selectively lacking MeCP2 in forebrain GABAergic neurons (Goffin et al, 2014), we examined how altering specific GABA-related signaling components would affect cortical excitatory discharge activity. We first tested whether stimulating $\mathrm{GABA}_{\mathrm{B}}$ receptors would affect network hyperexcitability using the $\mathrm{GABA}_{\mathrm{B}}$ receptor-positive allosteric modulator GS-39783, whose modulatory actions only affect $\mathrm{GABA}_{\mathrm{B}}$ receptors upon activation by endogenously released GABA (Pin and Prézeau, 2007; Froestl, 2010). At $2.5 \mathrm{mg} / \mathrm{kg}$, GS-39783 failed to induce cortical discharge activity in 14 of the 15 female wild-type mice examined (Figure 1). This same dose, however, elevated the discharge incidence rate of female $M e c p 2^{+/-}$mice from a baseline of $88.5 \pm 10.8$ to $143.9 \pm 14.8$ discharge events per hour $(p=0.0014 ; n=14$, Figure 4), but did not significantly alter the duration or waveform frequency of the discharges (Figure 4). The administration of a higher dose of GS-39783 (5 mg/kg) similarly increased the cortical discharge incidence rate in Mecp $2^{+/-}$mice from a baseline of $68.2 \pm 7.5$ to $124.4 \pm 15.4$ discharges per hour $(p=0.0002, n=14$, Figure 4$)$, and also lengthened the average discharge duration (to $1.6 \pm 0.1 \mathrm{~s}$ post-GS-39783 from $1.2 \pm 0.1 \mathrm{~s}$ baseline, $p=0.002$, Figure 4 ), and slowed discharge waveform frequency (from $8.1 \pm 0.2 \mathrm{~Hz}$ to $7.7 \pm 0.2 \mathrm{~Hz}, p=0.03$, Figure 4$)$. Interestingly, this same $5 \mathrm{mg} / \mathrm{kg}$ dose of GS-39783 was sufficient to induce short discharge-like events in all female wild-type mice tested ( $n=8$, Figure 1) that had discharge incidence rates $(42.8 \pm 11.0$ per hour), durations $(1.1 \pm 0.1 \mathrm{~s})$, and frequencies $(6.0 \pm 0.4 \mathrm{~Hz})$ that were similar to those seen in female $M e c p 2^{+/}$mice under baseline conditions (Figure 1 and Table 1).

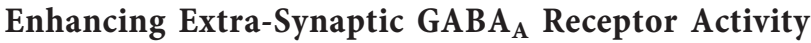 Decreases Cortical Excitatory Discharge Patterns in Female Mecp2 ${ }^{+/-}$Mice}

The enhancement of discharge activity with GS-39783, which requires $G_{A B A}$ receptors to be bound by GABA for its potentiating effects, suggests that GABA levels may be elevated in the $M e c p 2^{+/-}$mouse cortex. This is intriguing, as both the excessive stimulation of $\mathrm{GABA}_{\mathrm{B}}$ receptors 
(Snead, 1992) and the overstimulation of tonic extra-synaptic $\mathrm{GABA}_{\mathrm{A}}$ receptors can each induce cortical discharge activity in a variety of rodent seizure models (Cope et al, 2009). To test whether selective stimulation of extra-synaptic $\mathrm{GABA}_{\mathrm{A}}$ receptors would similarly exacerbate discharge activity, we administered THIP, which is a selective agonist for the $\mathrm{GABA}_{\mathrm{A}}$ receptor $\delta$-subunit found exclusively at extrasynaptic locations (Nusser et al, 1998; Brown et al, 2002).

Table I Epileptiform Discharge Properties Differ Between Male Mecp2-ly and Female Mecp2 ${ }^{+/-}$Mice

\begin{tabular}{|c|c|c|c|c|}
\hline Genotype & Discharge type & Discharges per hour & Discharge duration (s) & Discharge frequency $(\mathrm{Hz})$ \\
\hline |4- to |8-Month-old female wild type $(n=22)$ & None & 0 & NA & NA \\
\hline |4- to |8-Month-old female Mecp2 $2^{+/-}(n=24)$ & Short & $95.3 \pm 7.7$ & $1.1 \pm 0.1$ & $7.6 \pm 0.3$ \\
\hline 60- to 80-Day-old male $M e c p 2^{-1 y}(n=8)$ & Short & $41.2 \pm 8.8 *$ & $0.8 \pm 0.1$ & $6.1 \pm 0.3^{*}$ \\
\hline 60- to 80-Day-old male Mecp2-ly $(n=7)$ & Long & $2.5 \pm 0.7$ & $72.8 \pm 14.0$ & $5.5 \pm 0.3$ \\
\hline
\end{tabular}

Summary table of baseline incidences, durations, and frequency components of epileptiform discharge events observed in wild-type male, wild-type female,

$M e c p 2^{-1 y}$ male, and $M e c p 2^{+/-}$female mice. The incidence rate for 'short duration' discharge activity, and its average discharge frequency, differs significantly between male and female mutants (denoted by asterisk, $p=0.0003$ and $p=0.0099$, respectively; unpaired $t$-test). In contrast, the average duration of the short discharge events did not significantly differ between male and female mutants $(p=0.989)$. The parameters for the 'long duration' discharge events seen exclusively in male Mecp ${ }^{-l y}$ mice differed significantly from either the 'short duration' events present in the same male Mecp2-ly mice or the 'short duration' events present in I4- to I8-month-old female $M e c p 2^{+/-}$mice. No spike and wave discharges were observed in any of the male or female wild-type mice examined.
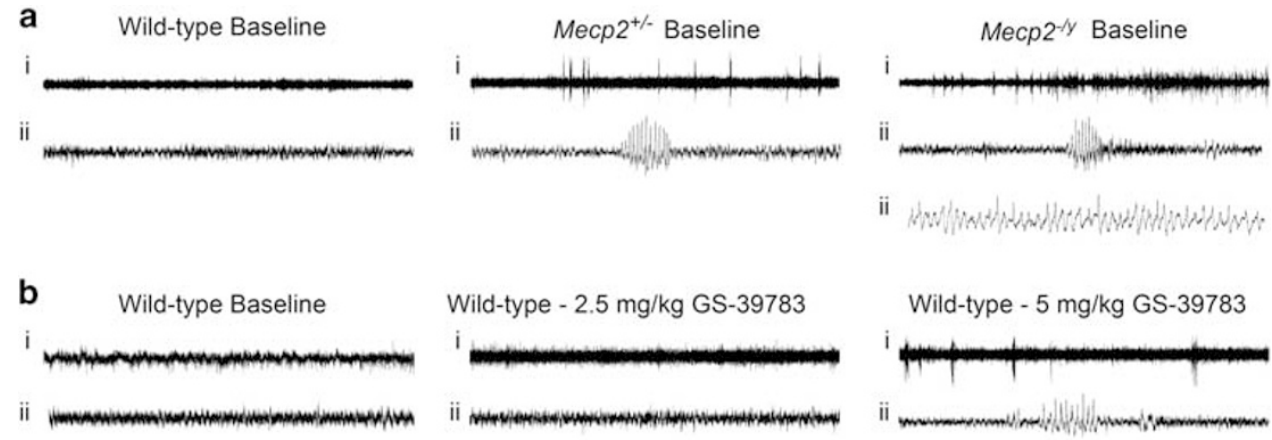

C

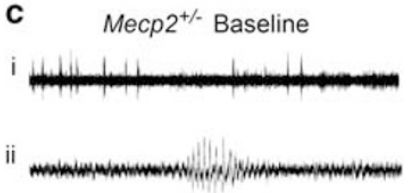

$M e c p 2^{+/-}-2.5 \mathrm{mg} / \mathrm{kg} \mathrm{GS}-39783$

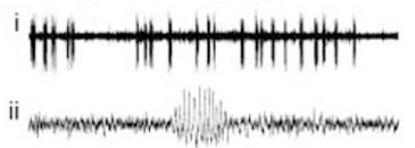

d

Wild-type Baseline
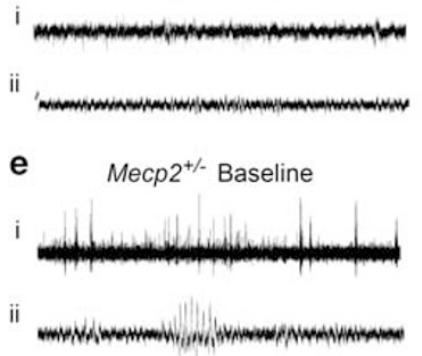

\begin{abstract}
Wild-type - $5 \mathrm{mg} / \mathrm{kg}$ THIP
\end{abstract}

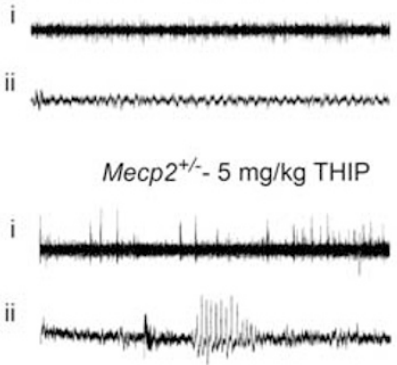

Mecp2-/y Baseline

Wild-type - 5 mg/kg GS-39783

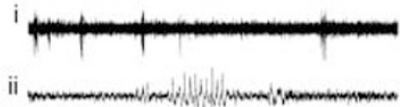

Mecp2 $^{+/}=5 \mathrm{mg} / \mathrm{kg} \mathrm{GS}-39783$

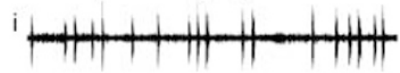

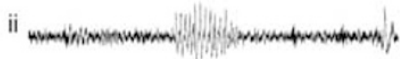

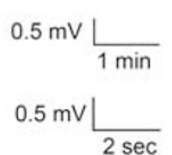

Figure I The GABA $A_{B}$ receptor-positive allosteric modulator GS-39783 exacerbates epileptiform discharge activity in female Mecp $2^{+/-}$mice, whereas the

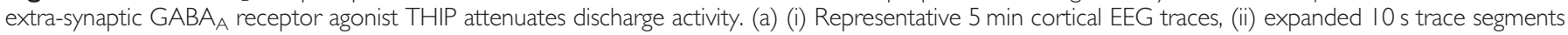
from a I4-month-old female wild-type mouse (left); a I4-month-old heterozygous female MeCP2-deficient mouse depicting typical short-duration discharge events (middle); and a 65-day-old male MeCP2-null mouse depicting both short-duration (ii) and long-duration (iii) discharge events (right). (b, c) Representative $5 \mathrm{~min}$ (i) and $10 \mathrm{~s}$ (ii) cortical EEG traces from 14- to 18 -month-old female wild-type and Mecp $2^{+/-}$mice under basal conditions (left panels) and following a $2.5-\mathrm{mg} / \mathrm{kg}$ dose (middle panels) or a $5.0-\mathrm{mg} / \mathrm{kg}$ dose (right panels) of the GABA $\mathrm{B}$ receptor-positive allosteric modulator GS-39783. Note the $2.5-\mathrm{mg} / \mathrm{kg}$ GS-39783 dose exaggerated discharge activity in female Mecp $2^{+/-}$mice without affecting wild-type mice, while at $5.0 \mathrm{mg} / \mathrm{kg}$ GS-39783 induced short duration discharge events in wild-type mice. $(\mathrm{d}, \mathrm{e})$ Representative EEG traces from wild-type and Mecp $2^{+/-}$mice following administration of 5 mg/kg of the extra-synaptic GABA $A_{A}$ receptor $\delta$-subunit agonist THIP. This concentration of THIP had no effect on EEG activity in wild-type mice, and attenuated discharge activity in female $M e c p 2^{+1-}$ mice. 
a

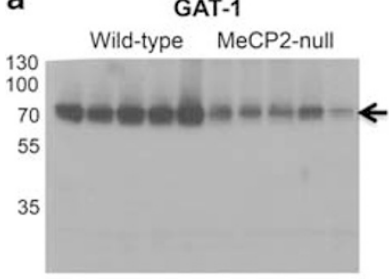

GAPDH

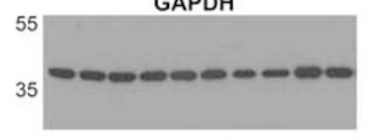

b

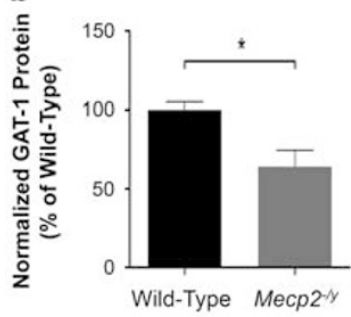

C

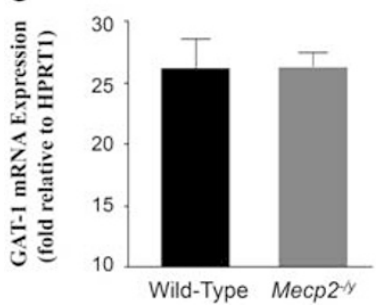

R2 Subunit

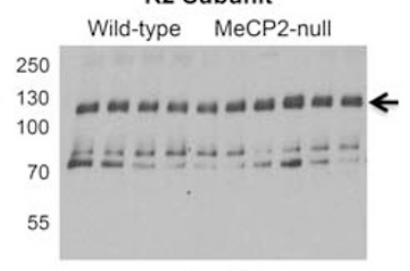

GAPDH
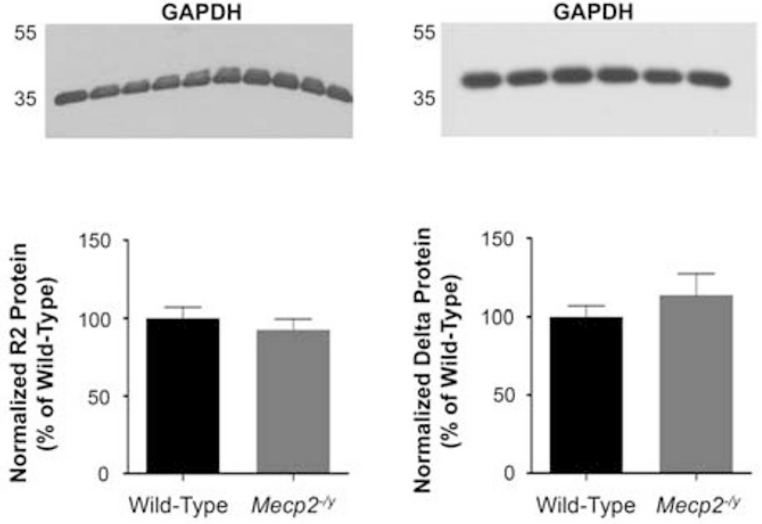

Figure 2 GAT-I protein levels, but not $G A B A_{B}$ receptor $R 2$ subunit or $G A B A_{A}$ receptor delta subunit levels, are diminished in the Mecp2 ${ }^{-1 y}$ mouse cortex. (a) Representative western blots illustrating the relative immunoreactive levels of GAT-I (left blot), the R2 subunit of GABA ${ }_{B}$ receptors (middle blot),

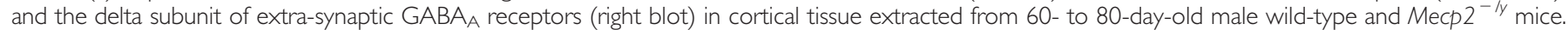
Arrows denote the product of the expected mass for each respective antibody. The level of GAPDH protein for each sample is shown as a protein loading control. (b) Histograms presenting the cumulative mean \pm SEM of the densitometric intensity data for examining GAT-I ( $n=13$ wild-type and $n=15$ MeCP2-null; 3 independent blots); the GABA $\mathrm{B}_{\mathrm{B}}$ receptor R2 subunit ( $n=12$ wild-type and $n=15$ MeCP2-null; 3 independent blots), and the delta subunit of extra-synaptic GABA $\mathrm{A}_{\mathrm{A}}$ receptors $(n=10$ wild-type and $n=10 \mathrm{MeCP}$-null; 2 independent blots) normalized to their corresponding GAPDH levels. In all histograms, the wild-type values have been set to $100 \%$. Asterisk denotes statistical significance $(p<0.05$, rank-sum test). (c) Histogram presenting the mean \pm SEM for GAT-I mRNA levels as determined by real-time PCR. The values represent fold differences in GAT-I expression in wild-type $(n=3)$ and male $\operatorname{Mecp}^{-1 y}(n=3)$ cortical samples relative to the expression of the internal reference HPRTI gene.

In female wild-type mice $(n=15)$, the administration of $5 \mathrm{mg} / \mathrm{kg}$ THIP failed to promote any discernible discharge activity (Figure 1) and had no overt sedative effects. In 14- to 18 -month-old female $M e c p 2^{+/-}$mice $(n=12)$, however, this same dose of THIP significantly decreased the cortical discharge incidence rate from a baseline of $71.8 \pm 12.2$ to $25.8 \pm 6.4$ discharges per hour $(p=0.0002$; Figures 1 and 4$)$, without significantly affecting either the discharge duration or the waveform frequency (Figures 1 and 4).

\section{GAT-1 Protein Levels, but not GABA $A_{B}$ or Extra-Synaptic $\mathrm{GABA}_{\mathrm{A}}$ Receptor Subunits, are Diminished in the MeCP2-Null Cortex}

The above results suggest that $\mathrm{GABA}_{\mathrm{B}}$ receptor tone is elevated in the MeCP2-deficient cortex. Such an effect could arise from increases in $\mathrm{GABA}_{\mathrm{B}}$ receptor prevalence, and/or from decreases in the expression or activity of GABA transport systems. Using western blotting, we compared the expression levels of the $\mathrm{GABA}_{B}$ receptor subunit $\mathrm{R} 2$, which is the requisite subunit for functional $G_{A B A}$ receptors (Bowery and Enna, 2000), as well as the expression of the extra-synaptic $\mathrm{GABA}_{\mathrm{A}}$ receptor subunit delta, and the GABA Transporter type 1 (GAT-1) - which is the primary transporter responsible for clearing synaptic GABA in the cortex (Conti et al, 2004)-between the wild-type and MeCP2-null cortex. These assessments focused on male mutants, as they display the more severe cortical hyper-excitable network phenotype, and allow us to avoid the expression variability seen in female mutants due to their mosaic MeCP2 expression patterns (Wither et al, 2013). No significant changes in expression were found for either the $G_{A B A}$ receptor R2 subunit or the $\mathrm{GABA}_{\mathrm{A}}$ receptor delta subunit (Figure 2). In contrast, the prevalence of GAT-1 in the same Mecp $2^{-/ y}$ mouse cortical samples was decreased by $34.4 \pm 10.7 \%$ from wild-type levels ( $p=0.007$, Figure 2$)$. This decrease in GAT-1 protein was not paralleled by decreases in cortical GAT-1 mRNA expression; however, although 

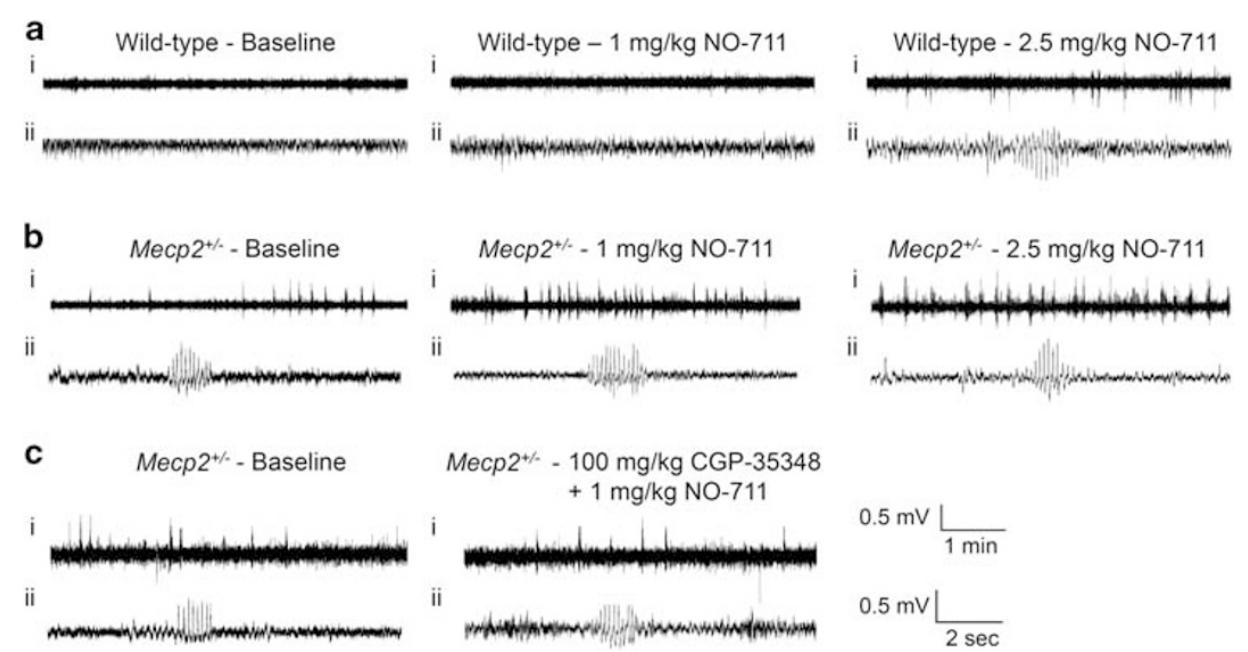

Figure 3 The GAT-I inhibitor NO-7II intensifies the epileptiform discharge phenotype of female Mecp $2^{+/-}$mice. Representative 5 min (i) and I0 s (ii) traces showing cortical EEG activity patterns seen in 14- to 18-month-old wild-type mice (a) or I4- to I8-month-old female Mecp2 ${ }^{+/-}$mice (b) under baseline conditions, and following the administration of the GAT-I inhibitor NO-7 I I at I.0 or $2.5 \mathrm{mg} / \mathrm{kg}$. Although no effects were observed in wild-type mice with the $1.0-\mathrm{mg} / \mathrm{kg}$ dose, a strong enhancement of discharge activity was observed in Mecp $2^{+1-}$ mice. A similar increase in discharge activity was observed in Mecp $2^{+1-}$ mice following the administration of a $2.5-\mathrm{mg} / \mathrm{kg}$ dose of $\mathrm{NO}-7 \mathrm{l}$. However, unlike the $1.0-\mathrm{mg} / \mathrm{kg}$ dose, the administration of $2.5 \mathrm{mg} / \mathrm{kg}$ dose of $\mathrm{NO}-7 \mathrm{I}$ I to female wild-type mice induced short duration discharge events similar to those seen in female Mecp $2^{+1-}$ mouse under basal conditions.

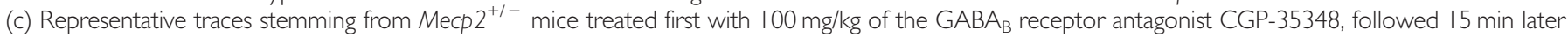
with $1.0 \mathrm{mg} / \mathrm{kg}$ of the GAT-I inhibitor NO-7 II are shown. Note the increase in discharge activity seen in (b) for the same dose of NO-7II is abolished by pre-treatment with the $\mathrm{GABA}_{\mathrm{B}}$ receptor antagonist.

chromatin immunoprecipitation assays confirmed that $\mathrm{MeCP} 2$ binds to the promoter region of the mouse GAT-1 gene in mouse cortical tissue (Supplementary Figure 1), no significant differences between GAT-1 mRNA were seen between cortical tissues from Mecp2 ${ }^{-1 y}$ and wild type by quantitative real-time PCR analysis (Figure 2). These data suggest the decreases in GAT-1 protein observed in the MeCP2-null cortex likely arise from post-transcriptional rather than transcriptional mechanisms. The decrease in GAT-1 protein is intriguing, as impaired GAT-1 enzymatic activity has been previously linked to the genesis of EEG discharge activity in cortical circuitries (Cope et al, 2009).

\section{GAT-1 Inhibition Increases the Severity of Discharge Events in Female Mecp2 ${ }^{+1-}$ Mice}

The decreased prevalence of GAT-1 protein provides a mechanism through which overstimulation of $\mathrm{GABA}_{\mathrm{B}}$ receptors could occur in the $\mathrm{MeCP} 2$-null cortex. If causal for network hyper-excitability, then further inhibition of the remaining GAT-1 in MeCP2-deficient mice should further exacerbate their discharge phenotype. To test this, we administered different doses of the selective GAT-1 inhibitor NO-711 (Borden, 1996) to both female Mecp2 $2^{+-}$mice and female wild-type mice. The administration of $1.0 \mathrm{mg} / \mathrm{kg}$ NO-711 failed to induce discharge activity in 12 of 14 wildtype mice examined (Figure 3), and only a single short discharge was seen in each of the other two mice (not shown). These results indicate that under normal conditions this level of GAT-1 inhibition is primarily inconsequential for wild-type mice. In female Mecp $2^{+/-}$mice $(n=12)$, however, this same $1.0 \mathrm{mg} / \mathrm{kg}$ dose of NO-711 significantly increased the discharge incidence rate from $108.4 \pm 13.9$ to $203.1 \pm 23.0$ events per hour $(p=0.0002$, Figures 3 and 4$)$, lengthened discharge duration from $1.2 \pm 0.1 \mathrm{~s}$ to $1.8 \pm 0.2 \mathrm{~s}$ $(p=0.011$, Figure 4$)$, and slowed the discharge waveform frequency from $7.7 \pm 0.2 \mathrm{~Hz}$ to $6.7 \pm 0.3 \mathrm{~Hz} \quad(p=0.0014$, Figure 4). The administration of a dose of $2.5 \mathrm{mg} / \mathrm{kg}$ NO-711 produced a similar effect in female $\mathrm{Mecp}^{+/-}$mice $(n=12)$ increasing discharge incidence rate from $86.9 \pm 9.7$ to $160.2 \pm 12.0$ events per hour ( $p=0.0001$, Figures 3 and 4$)$, lengthening discharge duration from $1.1 \pm 0.1 \mathrm{~s}$ to $2.1 \pm 0.3 \mathrm{~s}$ $(p=0.006$, Figure 4$)$, and slowing the discharge waveform frequency from $7.4 \pm 0.2 \mathrm{~Hz}$ to $6.3 \pm 0.2 \mathrm{~Hz} \quad(p=0.0001$, Figure 4). Interestingly, administering the $2.5-\mathrm{mg} / \mathrm{kg}$ dose of NO-711 was sufficient to induce 'short' duration discharge events in 10 of 10 female wild-type mice (Figure 3) that had properties similar to the short duration discharges of female $M e c p 2^{+/-}$mice under basal conditions with incidence rates of $25.3 \pm 13.4$ discharges per hour, discharge durations of $1.0 \pm 0.1 \mathrm{~s}$, and discharge frequencies of $6.7 \pm 0.6 \mathrm{~Hz}$. Collectively, these results not only illustrate the critical role of GAT-1 in regulating cortical network hyper-excitability in female $M e c p 2^{+/-}$mice, but also show that the progressive inhibition of GAT-1 can induce a discharge phenotype in wild-type mice that resembles that of female $\mathrm{Mecp}^{+/-}$mice under basal conditions.

\section{Attenuating $\mathrm{GABA}_{\mathrm{B}}$ Receptor Activity Decreases Cortical Epileptiform Discharges in Mecp2 $^{+/-}$Mice}

Given the positive effects on discharge activity seen with the $\mathrm{GABA}_{\mathrm{B}}$ receptor allosteric modulator GS-39783 and the elevated discharge activity seen with the GAT-1 inhibitor NO-711, we next tested whether blocking $\mathrm{GABA}_{\mathrm{B}}$ receptors would decrease the discharge activity of female Mecp $2^{+/-}$ mice. Indeed, the administration of the selective $\mathrm{GABA}_{\mathrm{B}}$ receptor antagonist CGP-35348 (100 mg/kg; Snead, 1992) 

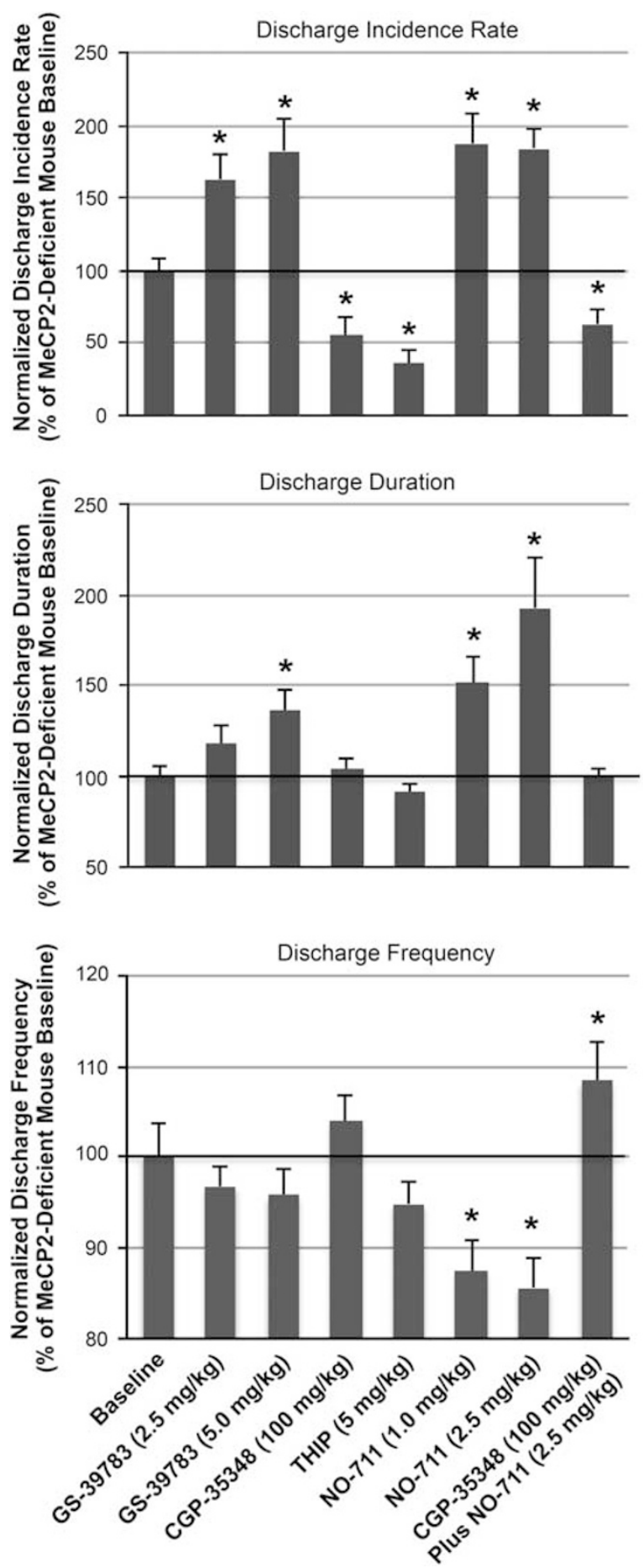

Figure 4 Cumulative effects of GABA modulating drugs on discharge properties in MeCP2-deficient mice. Histograms presenting the normalized mean and SEM for the different GABA modulating drugs tested on $n=12$ I5 female MeCP2-deficient mice. In each graph, the baseline discharge incidence rate (top panel), discharge duration (middle panel), and frequency (bottom panel) for each of drug and concentration as indicated. Baseline values before drug administration were set at 100\%, and the data presented indicate the percentage change from baseline for each condition. Asterisks denote statistical significance relative to MeCP2-deficient baseline $(p<0.05$; one-way ANOVA with Bonferroni post hoc correction). decreased the discharge incidence rate from $90.6 \pm 15.6$ to $50.0 \pm 11.4$ events per hour $(n=12 ; p=0.0016$, Figure 4$)$, but did not significantly affect average discharge duration or discharge frequency (Figure 4). Further, the preadministration of $100 \mathrm{mg} / \mathrm{kg}$ of the $\mathrm{GABA}_{\mathrm{B}}$ receptor blocker CGP-35348 $15 \mathrm{~min}$ before the administration of $1.0 \mathrm{mg} / \mathrm{kg}$ NO-711 completely prevented the increase in discharge activity seen in female $M e c p 2^{+/-}$mice treated with the same dose of only NO-711 $(n=12$; Figures 3 and 4$)$. In fact, discharge rates remained below baseline (from 106.7 \pm 12.4 to $67.2 \pm 7.5$ discharges per hour; $p=0.0014$ ), and the average frequency of the remaining discharges was also significantly increased (from $7.2 \pm 0.2 \mathrm{~Hz}$ to $7.8 \pm 0.2 \mathrm{~Hz}$; $p<0.001$; Figure 4). Collectively, these results strongly implicate enhanced $\mathrm{GABA}_{\mathrm{B}}$ receptor activity stemming from diminished GAT-1 clearance of synaptic GABA as a key driving force for the cortical network hyper-excitability phenotype of female $M e c p 2^{+/-}$mice.

\section{DISCUSSION}

Although neural network hyper-excitability is a major co-morbidity of Rett syndrome patients (Huppke et al, 2007), and also present in other conditions displaying errant MeCP2 expression (Gonzales and LaSalle, 2010), how impaired MeCP2 function leads to hyper-excitable neural circuits remains poorly understood. Using MeCP2-deficient mice as model systems and cortical epileptiform discharges as an index of network hyper-excitability, our results implicate enhanced GABAergic signaling as a contributing factor for the cortical discharge phenotype of $\mathrm{MeCP} 2$-deficient mice. Five principle findings emerge from our study: (1) cortical discharge patterns differ between male and female $\mathrm{MeCP} 2$-deficient mice, with male $\mathrm{MeCP}^{-/ y}$ mice displaying population of long duration discharges not seen in female $M e c p 2^{+/-}$mice; (2) cortical discharge patterns in female $M e c p 2^{+/-}$mice are exacerbated by enhancing $\mathrm{GABA}_{B}$ receptor activity and attenuated by $\mathrm{GABA}_{\mathrm{B}}$ receptor blockers; (3) the expression levels of GAT-1 are diminished in the MeCP2-deficient cortex; (4) the pattern of cortical discharges in female Mecp $2^{+/-}$ mice is exacerbated by inhibiting GAT-1 activity, and discharge activity can be induced in wild-type mice by more progressive GAT-1 inhibition; and (5) blocking $\mathrm{GABA}_{\mathrm{B}}$ receptors in female $M e c p 2^{+/-}$mice ameliorates the discharge activity increase induced by GAT-1 inhibition.

The overstimulation of $\mathrm{GABA}_{\mathrm{B}}$ receptors represents a recognized mechanism through which cortical discharge activity can be induced (Snead, 1992). Extra-synaptic levels of GABA are strongly regulated by GAT-1 activity (Conti et al, 2004), and decreasing the prevalence of activity of GAT-1 leads to increases in extracellular GABA levels and a heightening of both pre and postsynaptic $\mathrm{GABA}_{\mathrm{B}}$ receptor activity. Our data showing discharge activity is exacerbated in female $M e c p 2^{+/-}$mice by the $\mathrm{GABA}_{\mathrm{B}}$ receptor-positive allosteric modulator GS-39783-whose modulatory actions require $\mathrm{GABA}_{\mathrm{B}}$ receptors be activated by GABA (Pin and Prézeau, 2007; Froestl, 2010)—which are consistent with constitutively elevated $\mathrm{GABA}_{B}$ receptor activation in the $\mathrm{MeCP} 2$-deficient cortex. The increased excitatory discharge activity induced by doses of the GAT-1 inhibitor NO-711 
that had minimal or no effect on wild-type mice further supports this contention, as does the decreased discharge activity seen following the administration of the $\mathrm{GABA}_{\mathrm{B}}$ receptor antagonist CGP35348. These data therefore suggest that the decrease in GAT-1 prevalence in the MeCP2-deficient mouse cortex is rate-limiting for the establishment of a hyper-excitable cortical network, and that the discharge activity itself manifests through the enhanced activation of $\mathrm{GABA}_{\mathrm{B}}$ receptors. The observation that cortical discharges resembling those of $M e c p 2^{+/-}$mice can be induced in wild-type mice by increasing degrees of GAT-1 inhibition also supports this model.

Cortical GABAergic interneuronal networks are known to be involved in the initiation of cortical network hyperexcitability and seizures (Shiri et al, 2015). Recently, Goffin et al (2014) demonstrated that the large-scale loss of MeCP2 from forebrain GABAergic interneurons led to cortical hyper-excitability and behavioral seizures, whereas the restoration of MeCP2 in specific classes of interneurons in $\mathrm{MeCP} 2$-deficient mice ameliorated these deficits. However, the loss of MeCP2 from only excitatory neurons did not induce discharge activity. These results imply that the key $\mathrm{MeCP} 2$ target(s) responsible for the discharge phenotype are associated with cortical GABAergic interneurons. Our data indicate that decreased GAT-1 transporter expression in cortex regulates the discharge phenotype of MeCP2-deficient mice. It is therefore noteworthy that while some GAT-1 is expressed in astrocytes (Conti et al, 1998, 2004), the highest density of GAT-1 expression is found within GABAergic neurons (Chiu et al, 2002; Jensen et al, 2003; Conti et al, 1998), with inhibitory axon terminals in the neocortex displaying particularly high levels of GAT-1 expression (Chiu et al, 2002). Although we did not specifically assess the types of cells expressing GAT-1 in the MeCP2-deficient cortex, these collective results suggest that the decreases in GAT-1 expression we detect by immunoblotting, and those recently reported by Kang et al (2014) using immunohistochemistry, occur within the same forebrain inhibitory interneurons shown to be critical for epileptogenesis by Goffin et al (2014). These results therefore independently support the role of the GABAergic system in the manifestation of excitatory discharge activity in the MeCP2deficient brain.

An additional interesting question that arises from our observations is whether or how decreases in GAT-1 activity might affect phasic synaptic $\mathrm{GABA}_{\mathrm{A}}$ receptor activity. Indeed, phasic GABA signaling through synaptic $G_{A B A}$ receptors is altered in different regions of the MeCP2-deficient brain (Chao et al, 2010; Zhang et al, 2010; Jin et al, 2013), and has been proposed to be an underlying cause of local synaptic hyper-excitability (Chao et al, 2010). Although heightened extra-synaptic GABAergic tone may initially seem inconsistent with attenuated phasic GABAergic synaptic activity, the two are not mutually exclusive. In fact, GAT-1 knockout mice display precisely this phenotype. In GAT-1 knockout mice, enhanced tonic GABAergic tone arises from the diminished ability of GABA to be removed from synaptic areas (Jensen et al, 2003). However, these mice also display decreased phasic $\mathrm{GABA}_{\mathrm{A}}$ receptor activity due to the diminished frequency of spontaneously released GABA from presynaptic inhibitory terminals (Jensen et al, 2003). Thus, the enhanced activity of
$\mathrm{GABA}_{B}$ receptors we show here with GS-39783, and the decreased levels of phasic inhibition shown previously at MeCP2-deficient synapses (Chao et al, 2010; Jin et al, 2013), can co-exist in systems with decreased GAT-1 transporter activity. It is also noteworthy that many of the behavioral deficits and general phenotypes of GAT-1 knockout mice (Chiu et al, 2005; Liu et al, 2007) display considerable overlap with those of MeCP2-deficient mice (Katz et al, 2012). These include an impaired hind limb clasp reflex, pronounced tremor, decreased ambulatory and rearing activity, impaired balance, and altered anxiety responsiveness. Although these behavioral impairments are not unique to these two specific mutant mice, and additional work is required to establish whether or not MeCP2 and GAT-1 are functionally connected, the phenotypic overlap between the two lines is intriguing and suggestive of common or convergent network origins.

Finally, although our study focused on mechanisms of cortical network hyper-excitability in MeCP2-deficient mice, the observations we present raise the possibility that altered $\mathrm{MeCP} 2$ expression in other chronic or acute neurological conditions could secondarily cause decreases in GAT-1 expression in these conditions, and thereby further negatively affect their neural circuitry homeostasis. In this regard, relatively subtle decreases in $\mathrm{MeCP} 2$ expression are sufficient to induce behavioral impairments in mice (Samaco et al, 2008; Kerr et al, 2008), and decreases in brain MeCP2 levels have been reported in neurological conditions such as Angelman syndrome, attention deficit hyperactivity disorder, and general autism (Nagarajan et al, 2006; Neul, 2012; Gonzales and LaSalle, 2010). Thus, the neural link we illustrate here between MeCP2 and GAT-1 expression may be worthy of assessment in other conditions in which imbalances of excitatory and inhibitory tone are believed to have a role in pathogenesis.

\section{FUNDING AND DISCLOSURE}

The authors declare no conflict of interest.

\section{ACKNOWLEDGMENTS}

We thank G Zhang and R Logan for technical assistance, and members of the Eubanks, Snead, and Zhang laboratories for their comments on the manuscript. We also thank S Colic and B Bardakjian for helpful discussions on this study. This work was supported by an operating grant from the Canadian Institutes of Health Research to JHE (MOP-81104), and a HeART grant from the International Rett Syndrome Foundation to LZ and JHE. ML was the recipient of a University of Toronto Entry Fellowship.

\section{REFERENCES}

Amir RE, Van den Veyver IB, Wan M, Tran CQ, Francke U, Zoghbi HY (1999). Rett syndrome is caused by mutations in $\mathrm{X}$-linked MeCP2, encoding methyl-CpG-binding protein 2. Nat Genet 23: 185-188.

Asaka Y, Jugloff DG, Zhang L, Eubanks JH, Fitzsimonds RM (2006). Hippocampal synaptic plasticity is impaired in the MeCP2-null mouse model of Rett syndrome. Neurobiol Dis 21: 217-227. 
Borden LA (1996). GABA transporter heterogeneity: pharmacology and cellular localization. Neurochem Int 29: 335-356.

Bowery NG, Enna SJ (2000). Gamma-aminobutyric acid(B) receptors: first of the functional metabotropic heterodimers. J Pharmacol Exp Ther 292: 2-7.

Brown N, Kerby J, Bonnert TP, Whiting PJ, Wafford KA (2002). Pharmacological characterization of a novel cell line expressing human alpha(4)beta(3)delta GABA(A) receptors. Br J Pharmacol 136: 965-974.

Calfa G, Hablitz JJ, Pozzo-Miller L (2011). Network hyperexcitability in hippocampal slices from Mecp2 mutant mice revealed by voltage-sensitive dye imaging. J Neurophysiol 105: $1768-1784$.

Chao HT, Chen H, Samaco RC, Xue M, Chanrour M, Yoo J et al (2010). Dysfunction in GABA signalling mediates autismlike stereotypies and Rett syndrome phenotypes. Nature 468: 263-269.

Chiu CS, Brickley S, Jensen K, Southwell A, Mckinney S, Cull-Candy S et al (2005). GABA transporter deficiency causes tremor, ataxia, nervousness, and increased GABAinduced tonic conductance in cerebellum. J Neurosci 25: 3234-3245.

Chiu CS, Jensen K, Sokolova I, Wang D, Li M, Deshpande P et al (2002). Number, density, and surface/cytoplasmic distribution of GABA transporters at presynaptic structures of knock-in mice carrying GABA transporter subtype 1-green fluorescent protein fusions. J Neurosci 22: 10251-11066.

Conti F, Melone M, De Biasi S, Minelli A, Brecha NC, Ducati A (1998). Neuronal and glial localization of GAT-1, a high-affinity gamma-aminobutyric acid plasma membrane transporter, in human cerebral cortex: with a note on its distribution in monkey cortex. J Comp Neurol 396: 51-63.

Conti F, Minelli A, Melone M (2004). GABA transporters in the mammalian cerebral cortex: localization, development, and pathological implications. Brain Res Brain Res Rev 45: 196-212.

Cope DW, Di Giovanni G, Fyson SJ, Orbán G, Errington AC, Lorincz ML et al (2009). Enhanced tonic GABAA inhibition in typical absence epilepsy. Nat Med 15: 1392-1398.

D'Cruz JA, Wu C, Zahid T, El-Hayek Y, Zhang L, Eubanks JH (2010). Alterations of cortical and hippocampal EEG activity in MeCP2-deficient mice. Neurobiol Dis 38: 8-16.

Froestl W (2010). Chemistry and pharmacology of GABAB receptor ligands. Adv Pharmacol 58: 19-62.

Goffin D, Allen M, Zhang L, Amorim M, Wang IT, Reyes AR et al (2011). Rett syndrome mutation MeCP2 T158A disrupts DNA binding, protein stability and ERP responses. Nat Neurosci 15: 274-283.

Goffin D, Brodkin ES, Blendy JA, Siegel SJ, Zhou Z (2014). Cellular origins of auditory event-related potential deficits in Rett syndrome. Nat Neurosci 17: 804-806.

Gonzales ML, LaSalle JM (2010). The role of MeCP2 in brain development and neurodevelopmental disorders. Curr Psychiatry Rep 12: 127-134.

Guy J, Hendrich B, Holmes M, Martin JE, Bird A (2001). A mouse Mecp2-null mutation causes neurological symptoms that mimic Rett syndrome. Nat Genet 27: 322-326.

Huppke P, Köhler K, Brockmann K, Stettner GM, Gärtner J (2007). Treatment of epilepsy in Rett syndrome. Eur J Paediatr Neurol 11: $10-16$.

Jensen K, Chiu CS, Sokolova I, Lester HA, Mody I (2003). GABA transporter-1 (GAT1)-deficient mice: differential tonic activation of GABAA versus GABAB receptors in the hippocampus. J Neurophysiol 90: 2690-2701.

Jin X, Cui N, Zhong W, Jin XT, Jiang C (2013). GABAergic synaptic inputs of locus coeruleus neurons in wild-type and Mecp2-null mice. Am J Physiol Cell Physiol 304: C844-C857.
Jugloff DM, Vandamme K, Logan R, Visanji NP, Brotchie JM, Eubanks JH (2008). Targeted delivery of and MeCP2 transgene to forebrain neurons improves the behaviour of female MeCP2-deficient mice. Hum Mol Genet 17: 1386-1396.

Kang SK, Kim ST, Johnston MV, Kadam SD (2014). Temporal- and location-specific alterations of the GABA recycling system in Mecp2 KO mouse brains. J Cent Nerv Syst Dis 6: $21-28$.

Katz DM, Berger-Sweeney JE, Eubanks JH, Justice MJ, Neul JL, Pozzo-Miller L et al (2012). Preclinical research in Rett syndrome: setting the foundation for translational success. Dis Model Mech 5: 733-745.

Kerr B, Alvarez-Saavedra M, Sáez MA, Saona A, Young JI (2008). Defective body-weight regulation, motor control and abnormal social interactions in Mecp2 hypomorphic mice. Hum Mol Genet 17: $1707-1717$.

Lang $\mathrm{M}$, Wither RG, Brotchie JM, Wu C, Zhang L, Eubanks JH (2013). Selective preservation of MeCP2 in catecholaminergic cells is sufficient to improve the behavioral phenotype of male and female Mecp2-deficient mice. Hum Mol Genet 22: 358-371.

Lang M, Wither RG, Colic S, Wu C, Monnier PP, Bardakjian BL et al (2014). Rescue of behavioral and EEG deficits in male and female Mecp2-deficient mice by delayed Mecp2 gene reactivation. Hum Mol Genet 23: 303-318.

Liu GX, Cai GQ, Cai YQ, Sheng ZJ, Jiang J, Mei Z et al (2007). Reduced anxiety and depression-like behaviors in mice lacking GABA transporter subtype 1. Neuropsychopharmacology 32: 1531-1539.

McLeod F, Ganley R, Williams L, Selfridge J, Bird A, Cobb SR (2013). Reduced seizure threshold and altered network oscillatory properties in a mouse model of Rett syndrome. Neuroscience 231: 195-205.

Nagarajan RP, Hogart AR, Gwye Y, Martin MR, LaSalle JM (2006). Reduced MeCP2 expression is frequent in autism frontal cortex and correlates with aberrant MECP2 promoter methylation. Epigenetics 1: e1-e11.

Neul JL (2012). The relationship of Rett syndrome and MECP2 disorders to autism. Dialogues Clin Neurosci 14: 253-262.

Nusser Z, Sieghart W, Somogyi P (1998). Segregation of different GABAA receptors to synaptic and extrasynaptic membranes of cerebellar granule cells. J Neurosci 18: 1693-1703.

Pin JP, Prézeau L (2007). Allosteric modulators of GABA(B) receptors: mechanism of action and therapeutic perspective. Curr Neuropharmacol 5: 195-201.

Samaco RC, Fryer JD, Ren J, Fyffe S, Chao HT, Sun Y et al (2008). A partial loss of function allele of methyl-CpG-binding protein 2 predicts a human neurodevelopmental syndrome. Hum Mol Genet 17: 1718-1727.

Shahbazian M, Young J, Yuva-Paylor L, Spencer C, Antalffy B, Noebels J et al (2002). Mice with truncated MeCP2 recapitulate many Rett syndrome features and display hyperacetylation of histone H3. Neuron 35: 243-254.

Shiri Z, Manseau F, Levesque M, Williams S, Avoli M (2015). Interneuron activity leads to initiation of low-voltage fast-onset seizures. Ann Neurol 77: 541-546.

Sidorova-Darmos E, Wither RG, Shulyakova N, Fisher C, Ratnam M, Aarts M et al (2014). Differential expression of sirtuin family members in the developing, adult, and aged rat brain. Front Aging Neurosci 6: 333.

Snead OC 3rd (1992). Evidence for GABAB-mediated mechanisms in experimental generalized absence seizures. Eur J Pharmacol 213: 343-349.

Van Esch H, Bauters $M$, Ignatius J, Jansen M, Raynaud M, Hollanders $\mathrm{K}$ et al (2005). Duplication of the MECP2 region is a frequent cause of severe mental retardation and progressive neurological symptoms in males. Am J Hum Genet 77: $442-453$. 
Ward CS, Arvide EM, Huang TW, Yoo J, Noebels JL, Neul JL (2011). MeCP2 is critical within HoxB1-derived tissues of mice for normal lifespan. J Neurosci 31: 10359-10370.

Wither RG, Colic S, Wu C, Bardakjian BL, Zhang L, Eubanks JH (2012). Daily rhythmic behaviors and thermoregulatory patterns are disrupted in adult female MeCP2-deficient mice. PLoS One 7: e35396.

Wither RG, Lang M, Zhang L, Eubanks JH (2013). Regional MeCP2 expression levels in the female MeCP2-deficient mouse brain correlate with specific behavioral impairments. Exp Neurol 239: 49-59.
Wu C, Wais M, Sheppy E, del Campo M, Zhang L (2008). A glue-based, screw-free method of implantation of intra-cranial electrodes in young mice. J Neurosci Methods 171: 126-131.

Zhang L, He J, Jugloff DG, Eubanks JH (2008). The MeCP2-null hippocampus displays altered basal inhibitory rhythms and is prone to hyperexcitability. Hippocampus 18: 294-309.

Zhang ZW, Zak JD, Lui H (2010). MeCP2 is required for normal development of GABAergic circuits in the thalamus. J Neurophysiol 103: 2470-2481.

Supplementary Information accompanies the paper on the Neuropsychopharmacology website (http://www.nature.com/npp) 